\title{
Genetic structure of Triatoma venosa (Hemiptera: Reduviidae): molecular and morphometric evidence
}

\author{
Erika Vargas, Claudia Espitia, Carlos Patiño, Nestor Pinto, Germán Aguilera, \\ Carlos Jaramillo, María Dolores Bargues*, Felipe Guhl/ ${ }^{+}$
}

\author{
Centro de Investigaciones en Microbiología y Parasitología Tropical, Facultad de Ciencias, Universidad de los Andes, \\ A. Aéreo 4976, Bogotá, Colombia *Departamento de Parasitología, Facultad de Farmacia, \\ Universidad de Valencia, Valencia, España
}

\begin{abstract}
Triatoma venosa presents a restricted geographical distribution in America and is considered as a secondary vector of Chagas disease in Colombia and Ecuador. A total of 120 adult insects were collected in domestic and peridomestic habitats in an endemic area of the department of Boyacá, Colombia, in order to determine their genetic structure through morphometric and molecular techniques. The head and wings of each specimen were used for the analyses of size, shape, and sexual dimorphism. A significant sexual dimorphism was found, although no differences in size among the studied groups were detected. Differences were found in the analyzed structures except for male heads.

DNA was extracted from the legs in order to carry out the internal transcriber space-2 (ITS-2) amplification and the randon amplified polymorphic DNA (RAPD) analyses. Length polymorphisms were not detected in the ITS-2. Fst and $\mathrm{Nm}$ values were estimated (0.047 and 3.4, respectively). The high genetic flow found among the insects captured in the domicile and peridomiciliary environment does not permit a genetic differentiation, thus establishing the peridomicile as an important place for epidemiological surveillance.
\end{abstract}

Key words: Triatoma venosa - geometric morphometry - internal transcriber space-2 - random amplified polymorphic DNA vector control

In Colombia, 24 species of triatomines have been reported and of these 15 have been found naturally infected with Trypanosoma cruzi. Rhodnius prolixus, Triatoma dimidiata, Triatoma maculata, and Triatoma venosa are among the most important vectors (Guhl et al. 2002). T venosa (Stål) (Hemiptera: Reduviidae) is a secondary vector of Chagas disease that is frequently found in domiciles and peridomiciles in active vectorial transmission areas. Its habits and hosts are unknown. Abad-Franch et al. (2001) have reported wild forms of T. venosa in Ecuador and D'Alessandro et al. (1981) reported domiciliated T. venosa nymphs and adults infected with T. cruzi (identified by morphology) located in the Magdalena river valley and the western Andean mountain in Colombia (1600$2200 \mathrm{~m}$ above sea level). Morphometric and molecular analyses are important tools that provide evidence of the population structure of insect vectors. Studies by Diotaiuti et al. (2000) suggest that wild insect populations have the capacity to reinvade habitats that have been treated with insecticides, and Borges et al. (2005) report the existence of a connection between wild populations and popula-

Financial support: COLCIENCIAS project No. 459-2002 and CDIA-EC, European Community Contract No. ICA4-CT-200310049 and Project No. 3042/2000 Dirección General de Cooperación para el desarrollo, Presidencia de Gobierno de la Generalitat Valenciana, Valencia, Spain.

+Corresponding author: fguhl@uniandes.edu.co

Received 4 August 2005

Accepted 28 December 2005 tions' domiciles for T. brasiliensis based in the analysis of head morphometry and random amplified polymorphic DNA (RAPD) patrons. We report evidence for a homogeneous genetic structure of $T$. venosa by geometric morphometry, internal transcriber space-2 (ITS-2) amplification, and RAPDs analysis. This information will contribute to the epidemiological surveillance of Chagas disease vector control programmes.

\section{MATERIALS AND METHODS}

\section{Insects}

The samples were collected in the municipalities of Guateque and Somondoco, Boyacá Department, Colombia. All insects were classified as T. venosa in accordance with Lent and Wygodzinsky (1979).

A total of 120 individuals were analyzed: 30 domestic females and 30 domestic males (captured within houses) and 30 peridomestic females and 30 peridomestic males (captured within chicken coops). All of the insects were used in the morphometric analysis and half from each group was used in the molecular studies.

The municipality of Guateque is located $1840 \mathrm{~m}$ above sea level $\left(5^{\circ} 01^{\prime} \mathrm{N}\right.$ and $\left.73^{\circ} 29^{\prime} \mathrm{W}\right)$ with an average temperature of $18^{\circ} \mathrm{C}$. The municipality of Somondoco is located $1704 \mathrm{~m}$ above sea level (4⒌' $\mathrm{N}$ and $73^{\circ} 26^{\prime} \mathrm{E}$ ) with an average temperature of $19^{\circ} \mathrm{C}$ (Fig. 1).

These two municipalities are classified as humid premontane forest, in accordance with Holdridge's life zones (Espinal \& Montenegro 1980).

\section{Geometric morphometry}

Morphometric measurements - The head of each insect was placed on a triangular shaped marked card and 

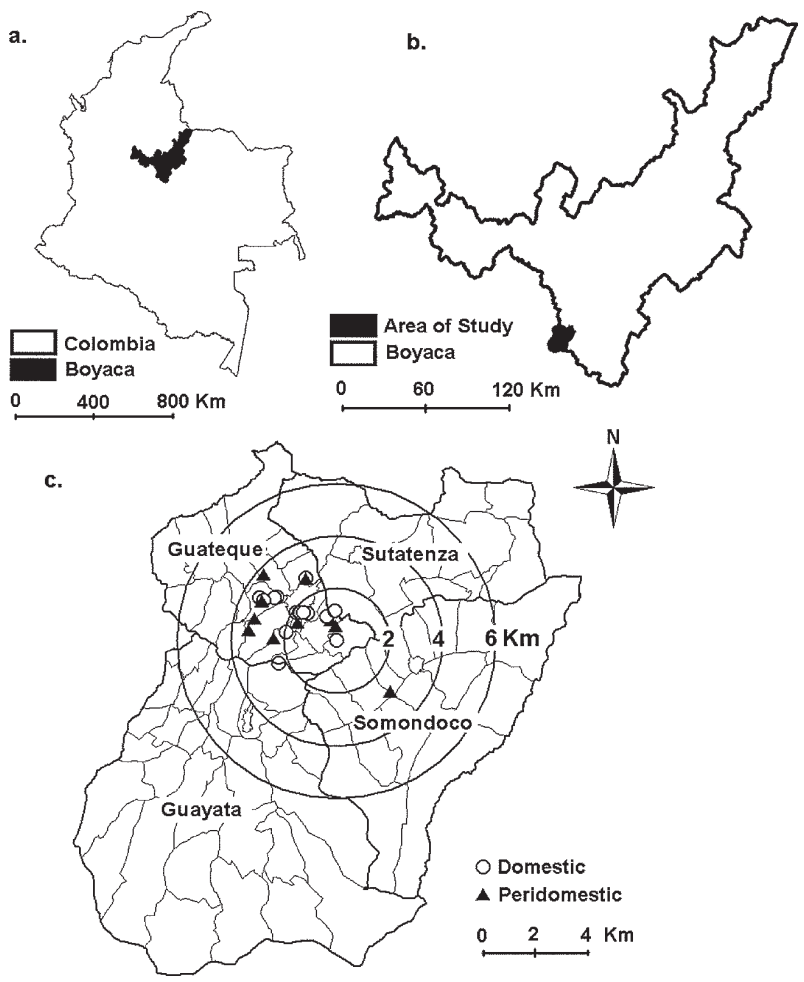

Fig. 1: geographical location of the studied area. a: location of Boyacá Department in Colombia; b: location of the municipalities of Guateque and Somondoco in Boyacá; c: capture sites of Triatoma venosa in the domicile and peridomicile.

held by a pin. The wings were mounted on an inclusion medium between a slide and a cover slip (Jaramillo et al. 2002). For the digitalization of images, a Nikon $® 4500$ digital photographic camera was used, adapted to a Nikon® SMZ800 stereomicroscope. From the head, 14 landmarks were selected, and 10 from the wings (Fig. 2). These points were transformed into geometric coordinates using the TpsDig 1.40 program (Rohlf 2003a), so as to obtain matrices of the average coordinates after taking three measurements. For the analyses of morphometric differences, the head and wing matrices were tabulated by sex, and for
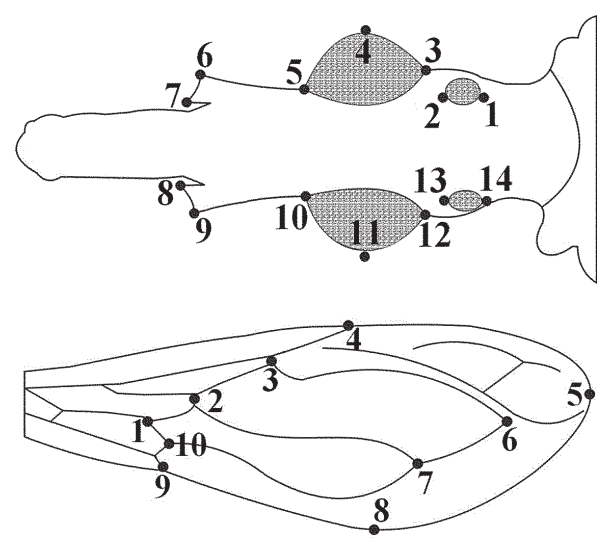

Fig. 2: landmarks taken as reference for Triatoma venosa heads and wings measurements. the sexual dimorphism analyses, the male and female matrices were put together.

Morphometric analyses - For the size analyses, the centroid size (CS) was used as an isometric estimator of size. For the shape analyses, the average coordinate matrices, superimposed through the Generalized Procrustes Analysis (GPA) (Rohlf 1990), were used to obtain the shape variables as uniform components (global deformations) and non uniform components (local deformations). These analyses were done using the tpsRelw 1.39 program (Rohlf 2003b).

Allometries - The relationship between the shape variables and the CS was analyzed through a linear regression and subsequently the comparison between the allometric slopes was done through a multivariate analysis of the covariance (MANCOVA), using the tpsRegr 1.28 program (Rohlf 2000).

Statistical analyses - A canonical variable analysis was calculated using the conformation variables and the numerical values of the head and wings of each insect were projected over the first factor to detect differences among compared groups. For the size analyses, the average comparisons were done with t-Student or Welch ANOVA statistical analyses, depending on the existence or non-existence of homogeneity variances using the PAST 1.18 program (Hammer et al. 2003).

\section{Molecular techniques}

DNA extraction - The six legs of each individual, previously washed and disinfected, were crushed, followed by a purification procedure with the Aqua Pure ${ }^{\circledR}$ kit for the isolation of DNA from BIO-RAD®. The DNA was kept at $-20^{\circ} \mathrm{C}$ until its analysis.

ITS-2 amplification - Specie specific primers were designed with the E-primer3® program based on an ITS-2 rDNA sequence (GenBank: AJ582026) of T. venosa insect captured in the same sampling area, VEN1 (5'AATTTTCGGTTTTACCCCCA-3') and VEN2 (5'AAAATCGCCCAGACTATGC-3'). The polymerase chain reaction $(\mathrm{PCR})$ technique was performed using the PureTaq Ready-To-Go PCR Beads kit (Amersham Biosciences $®)$, each bead was hydrated with $17.75 \mu$ l of PCR water, 1 $\mathrm{pmol} / \mu \mathrm{l}$ of each primer were added and $2 \mathrm{Mm} \mathrm{MgCl} 2$. The content was divided into two tubes and $2.5 \mu \mathrm{l}$ of total DNA were added in each tube $(15 \mathrm{ng} / \mu \mathrm{l})$, for a final reaction volume of $12.5 \mu$ l. This PCR program was reported by Jaramillo et al. (2001). The amplification products were evidenced through $1.5 \%$ agarose gel electrophoresis at $60 \mathrm{~V}$ during $1 \mathrm{~h}$. Gels were stained with ethidium bromide, and observed under UV light. The digitalization of the images and the determination of the molecular weights of the amplification products were done with the Quantity One ${ }^{\circledR}$ program.

RAPDs - The DNA of 30 individuals captured in the domicile and of 30 captured in the peridomicile was analyzed with the RTG primers (Amersham Biosciences $\left.{ }^{\circledR}\right)$ : 2 (5'-GTTTCGCTCC-3'), 3 (5'-GTAGACCCGT-3'), 4 (5'AAGAGCCCGT-3') and 5 (5'-AACGCGCAAC-3'), which allowed the obtaining of a total of 70 markers. 
The Ready to Go RAPD kit (Amersham Biosciences ${ }^{\circledR}$ ) was used, each bead was hydrated with $19 \mu 1$ of PCR water and $25 \mathrm{pmol}$ of each primer were added $(5 \mu \mathrm{l})$. Afterwards, the content was divided into four tubes, and $2 \mu 1$ of DNA was added to each one in order to obtain a final reaction volume of $8 \mu \mathrm{l}$. The visualization of the RAPDs products was done in polyacrylamide gel at $6 \%$ with an electrophoretic running time of $3 \mathrm{~h}$ at $80 \mathrm{~V}$, dyed with silver (Espitia et al. 2004).

Dendrograms - For the analysis, it is assumed that the T. venosa insects are in Hardy-Weinberg equilibrium and therefore no selection processes favoring any particular genotype. Binary matrices were built from RAPD gels, according to Welsh et al. (1992) in which the genetic information collected is represented for each individual. The matrix was analyzed with the RAPDPLOT program (Kambhampati et al. 1992), which generates a distances matrix using the Nei and Li (1979) similarity index. From here on, using the RAPDPLOT and NEIGHBOR (PHYLIP 3.5C) programs, a dendrogram was obtained using the UPGMA (Unweighted Pair Group Method of Arithmetic Averages) algorithm introduced by Sneath and Sokal (1973). The Nei (1973) genetic distances were calculated with the RAPDDIST programs. For a better visualization of the generated dendrograms the TreeView program (Roderic 1996) was used.

Genetic flow and dispersion potential - Wright's fixation index (Fst) and the migration effective rate (Nm) were estimated by RAPDFST program.

Additionally, the binary matrix data was run in the POPGENE program, version 1.31, which allowed the estimation of both, the genetic flow between groups (Gst) (Slatkin \& Barton 1989) and the effective rate of migration (Nm). It has been assumed that the alleles detected through RAPDs segregate in a Mendelian way, the bands that migrate in a same position are homologous, the loci segregate in an independent way and the studied $T$. venosa groups are in Hardy-Weinberg equilibrium.

\section{RESULTS}

\section{Geometric morphometry}

Size analyses - Sexual dimorphism was significant in domestic and peridomestic groups of the analyzed structures (Fig. 3), the females being larger than the males. In the analyses considering the ecotopes (domicilian/ peridomicilian) within sexes no significant differences were found (Fig. 4).

Shape and allometry analyses - Significant differences were found in all the studied structures except for the male heads (Fig. 5). Through the discriminant analysis, $91 \%$ of the domestic and peridomestic females and $86 \%$ of the domestic and peridomestic males were correctly classified. In the female wings and the male heads where allometry was detected, the MANCOVA was not significant $(p>0.05)$. No allometry was found in female heads or male wings.

\section{Molecular analyses}

ITS-2 Amplification - With the VEN1 and VEN2 prim- ers, no length polymorphisms were detected, presenting an amplification product of $244 \mathrm{pb}$ (Fig. 6).

$R A P D s$ - No specific pattern was observed for the insects collected in the domicile or peridomicile environment (Fig. 7). The homogeneity obtained in the banding

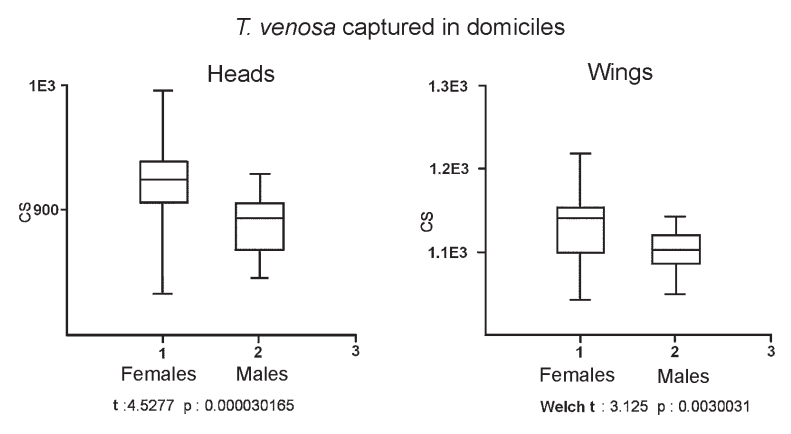

$T$. venosa captures in peridomiciles

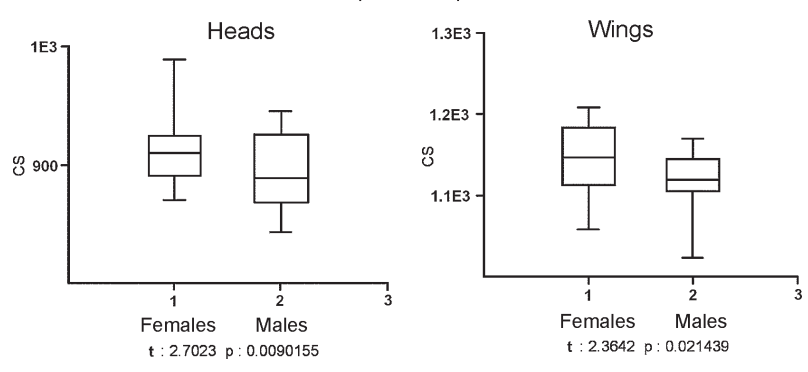

Fig. 3: size differences in heads and wings in specimens of Triatoma venosa captured in domicile and peridomicile. The arithmetic media can be observed as a line that divides the boxes in two. The ends of the boxes correspond to quantiles 25 and 75 , the vertical lines show the maximum and minimum value of the distribution.

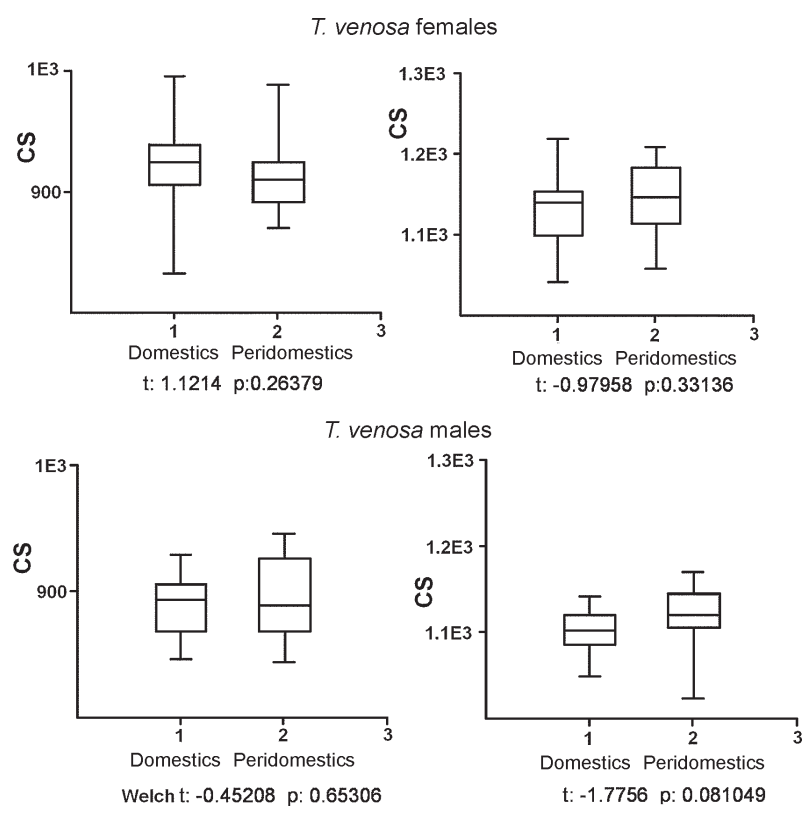

Fig. 4: size differences between groups in heads (left) and wings (right) of males and females in domestic and peridomestic groups of Triatoma venosa. The arithmetic average can be observed as a line that divides the boxes in two. The ends of the boxes correspond to quantiles 25 and 75; the vertical lines show the maximum and minimum value of the distribution. 

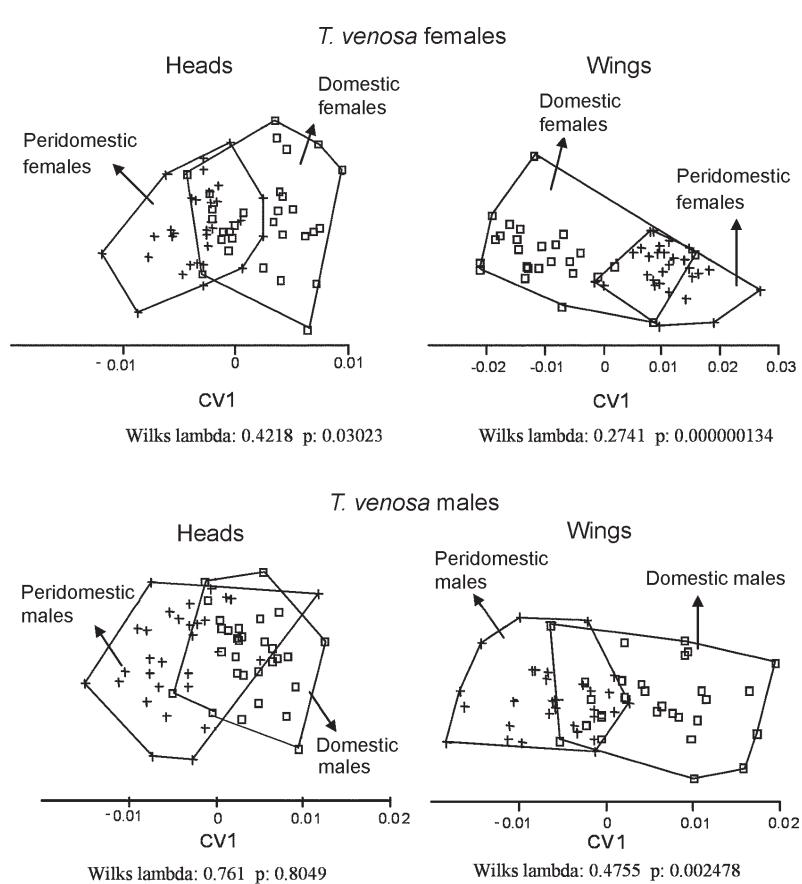

Fig. 5: shape differences of Triatoma venosa captured in domicile and peridomicile, through a Canonical Variate Analysis, on the shape variables.

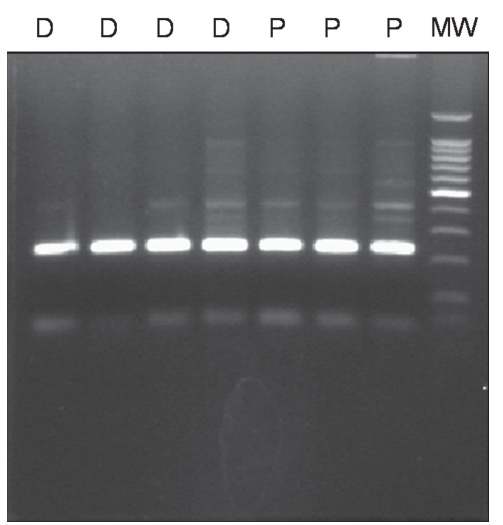

Fig. 6: amplification product of Triatoma venosa using the species specific primers VEN1 and VEN2. Insects captured in domiciles (D), insects captured in peridomiciles (P). MW: molecular weight marker of $100 \mathrm{pb}$

patterns suggests a low genetic differentiation between the $T$. venosa individuals captured inside and outside the domicile, which coincides with the analysis done with the RAPDPLOT program, where no particular grouping by sex or by place of capture was observed (Fig. 8), as well as with the analysis with the RAPDIST program, where a genetic distance of about 0.00865 was estimated among the insects grouped by place of capture (Fig. 9).

Analysis with the RAPDFST program resulted in an Fst value of 0.047 by Wright's methodology (Wright 1931) and the estimated Nm value was of 3.4. These results coincide with the analysis of the POPGENE program, where the estimated Gst was of 0.0499 , and the Nm of 9.5253 .

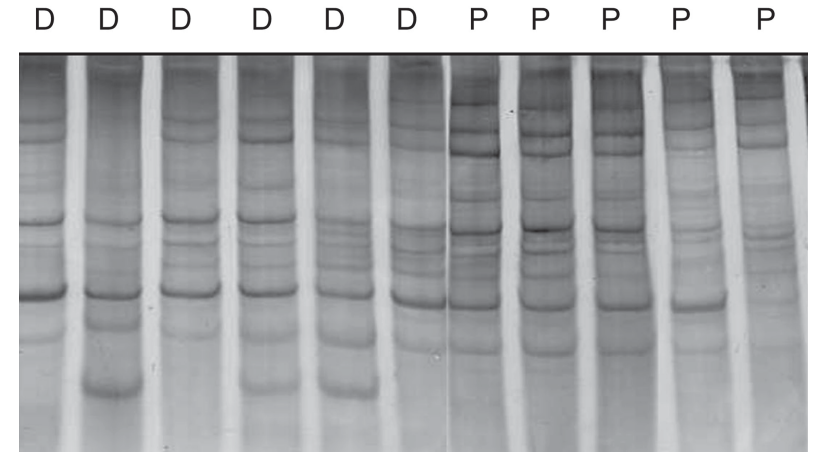

Fig. 7: acrylamide gels at 6\% dyed with silver. Amplification products through RAPDs with the RTG 2 for individuals of Triatoma venosa captured in domicile (D) and peridomicile $(\mathrm{P})$.

\section{DISCUSSION}

T. venosa, a secondary vector of Chagas disease in Colombia and Ecuador, has also been reported in Costa Rica (Lent \& Wygodzinsky 1979). Information about the biology and dispersion of this insect is very limited.

Both geometric morphometry and molecular analysis are tools that contribute to the knowledge of the genetic structure of triatomines and generate useful information in order to establish more effective strategies of vector control. Geometric morphometry permits the gathering of information on the size and shape of the organisms apart from the environmental factors (Jaramillo et al. 2002), thus permitting the collection of useful data from the phenotype variations which reflect possible changes in the genotype that must be corroborated through molecular techniques such as RAPDs and the ITS-2 amplification.

The evidence of sexual dimorphism in the Triatominae is widely known, the females presenting greater size than the males (Lent \& Wygodzinsky 1979). According to the sexual dimorphism reduction reported by Dujardin et al. (1999) the domiciliation process of triatomines in transition from a natural habitat to an artificial one leads to a reduction of such dimorphism. The stated sexual dimorphism found in the studied groups of T. venosa suggests a recent invasion process of the artificial ecotopes.

The size of the triatomines can be modified as a response to environmental changes (Jaramillo et al. 2002). After doing the group analysis according to the different ecotopes (domicile and peridomicile) no significant size differences were found, again, this suggests an active mobility of $T$. venosa between both environments.

In terms of shape, no significant differences were found in the male heads. In female heads, according to the multivariate regression, the existence of allometries and the comparison of allometric slopes between sexes were not significant. This means that the shape differences can be explained by a relation with size and not by the belonging to domestic and peridomestic groups. In female heads and male wings the shape differences are not explained by size because no allometries were detected as a group feature, instead, they are the individuals' own characteristics.

Discriminant analyses were used to determine which variables discriminate between the two groups under 
study. This analysis allowed grouping the insects in accordance to the place of capture in contrast to the molecular analyses. It is possible that this grouping could be due to the phenotypic plasticity, the expression of different phenotypes in single genotype when subjected to different environments (Whitman 2005).

When estimating the Fst through molecular analyses, the obtained value $(0.047)$ shows little genetic differentiation according to Wright's classification (Wright 1978).
However, T. venosa presents a larger genetic flow than that reported for Triatoma dimidiata in Colombia (Ramirez et al. 2005), or for butterflies such as Papilo glaucus in Ohio, Georgia, and Florida (Bossart \& Scriber 1995).

The estimated Nm value (3.4 migrating insects per generation) shows a potential dispersion enough to maintain genetic homogeneity, which keeps the allelic frequencies in the populations (Wright 1931). The absence of length polymorphisms in the ITS-2 (Fig. 6) and the dendrogram

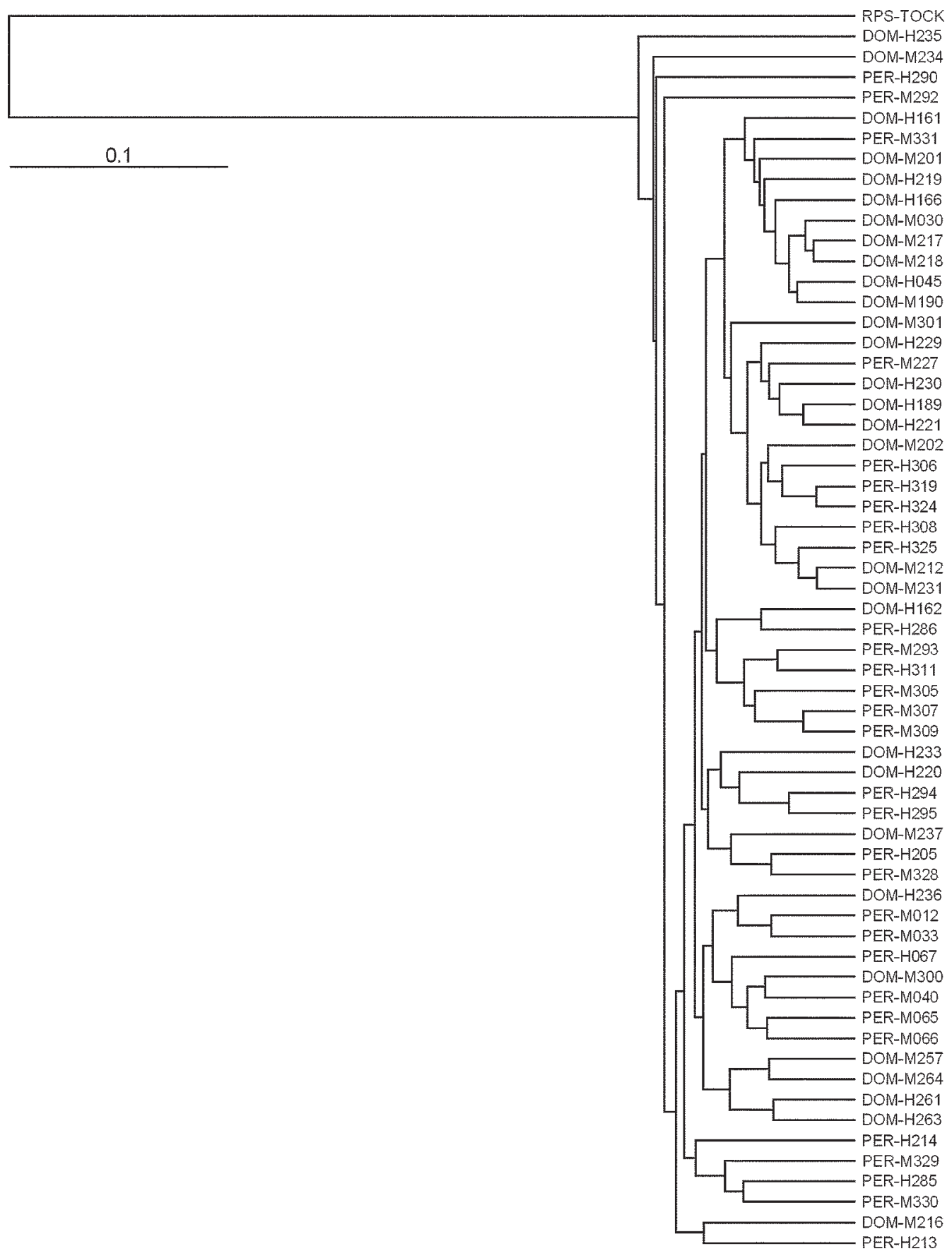

Fig. 8: dendrogram of the Triatoma venosa individuals generated with RAPDPLOT Based on Nei and Li (1979) genetic distance, and on the UPGMA method, for 70 loci. Rhodnius prolixus (RPS) was used as the exclusion group. PER: insects captured in peridomicile, DOM: insects captured in domicile; M: male, H: female. 


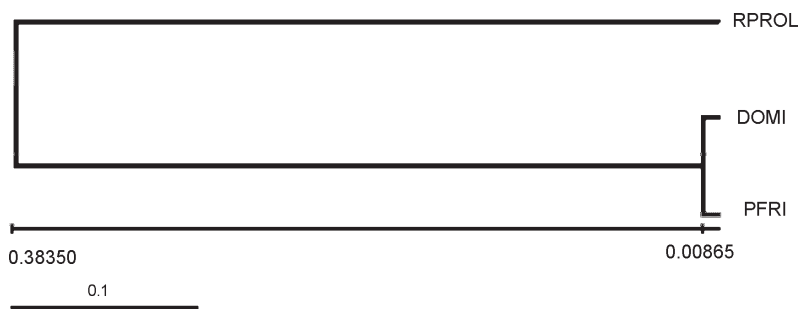

Fig. 9: dendrogram of the Triatoma venosa individuals grouped by ecotope domicile (DOMI) and peridomicile (PERI), based on Nei's genetic distance (Nei 1972), the UPGMA method with 1000 bootstrapping. Rhodnius prolixus (RPRO) was used as an exclusion group generated with RAPDPLOT.

generated from the RAPDs (Fig. 8) showed no specific grouping of the insects suggesting a genetic homogeneity of $T$. venosa in the area of study.

These results suggest the mobility of insects between both environments and/or a recent invasion of the artificial ecotopes from the wilderness and a high genetic flow that does not permit a genetic differentiation among the triatomines captured in the domicile and the peridomicile. It can be said that the insects studied belong to the same population, thus establishing the peridomicile as an important place for epidemiological surveillance in control programs, allowing to understand the behavior of triatomines that have the ability to reinfest dwellings. Control in the peridomicile must also be done so as to prevent reinfestation.

The relevance of $T$. venosa in the transmission of Chagas disease is currently unknown, the rate of infection with trypanosomes has not been reported and due to the high genetic flow here reported, it could be a potential vector for $T$. cruzi transmission that should to be considered in epidemiological surveillance in the future. Additionally, as Whitman (2005) reports, phenotypic plasticity deserves increased attention by those involved in studies on biological diversity and is of practical concern for agricultural and medical Entomology.

\section{ACKNOWLEDGEMENTS}

To Dr Nicolás Jaramillo for his valuable scientific contributions and the staff at Secretaría Departamental de Salud de Boyacá.

\section{REFERENCES}

Abad-Franch F, Paucar A, Carpio C, Cuba CA, Aguilar HM, Miles MA 2001. Biogeography of Triatominae (Hemiptera: Reduviidae) in Ecuador: implications for the design of control strategies. Mem Inst Oswaldo Cruz 96: 611-620.

Borges EC, Dujardin JP, Schofield CJ, Romanha AJ, Diotaiuti L 2005. Dynamics between sylvatic, peridomestic and domestic populations of Triatoma brasiliensis (Hemiptera: Reduviidae) in Ceará State, Notheastern Brazil. Acta Trop Jan 93: 119-126.

Bossart JL, Scriber JM 1995. Maintenance of ecologically significant genetic variation in the tiger swallowtail butterfly through differential selection and gene flow. Evolution 49: 1163-1171.
D’Alessandro A, Barreto P, Thomas M 1981. Nuevos registros de triatominos domiciliarios y extradomiciliarios en Colombia. Col Med 12: 75-85.

Diotaiuti L, Faria Filho OF, Carneiro FCF, Dias JCP, Pires HHR, Schofield CJ 2000. Operacional aspects of Triatoma brasiliensis control. Cad Saúde Públ 16: 61-68.

Dujardin JP, Panzera P, Schofield CJ 1999. Triatominae as a model of morphological plasticity under ecological pressure. Mem Inst Oswaldo Cruz 94: 223-228.

Espinal S, Montenegro M 1980. Zonas de Vida o Formaciones Vegetales de Colombia, Memoria Explicativa sobre el Mapa ecológico de Colombia, Instituto Geográfico "Agustín Codazzi”, Departamento Agrológico, Imprenta Canal Ramirez, Colombia, p. 91-94.

Espitia E, Jaramillo C, Aguilera C, Pinto N, Guhl F 2004. Estudio preliminar de la estructura genética de Triatoma venosa (Hemíptera: Reduviidae) mediante marcadores moleculares RAPDs. Rev Colomb Entomol 30: 157-160.

Guhl F, Montoya R, Pinto N, Aguilera G, Davies C, CampbellDendrum D 2002. Efecto del clima y del medio ambiente en la distribución de triatominos y enfermedad de Chagas en Colombia. Biomedica 22: 35.

Hammer Ø, Harper DAT, Ryan PD 2001. PAST: Paleontological Statistics Software Package for Education and Data Analysis. Palaeontologia Electronica 4: 9pp. http://palaeoelectronica.org/2001_1/past/issue1_01.htm

Jaramillo C, Montaña MF, Castro L, Vallejo G, Guhl F 2001. Differentiation and genetic analysis of Rhodnius prolixus and Rhodnius colombiensis by rDNA and random amplified polymorphic DNA. Mem Inst Oswaldo Cruz 96: 10431048.

Jaramillo N, Castillo D, Wolff M 2002. Geometric morphometric differences between Pastrongylus geniculatus from field and laboratory. Mem Inst Oswaldo Cruz 97: 667-673.

Kambhampati S, Black WC4 $4^{\text {th }}$, Rai KS 1992. Random amplified polymorphic DNA of mosquito species and populations (Diptera: Culicidae): techniques, statistical analysis, and applications. J Med Entomol 29: 939-945.

Lent H, Wygodzinsky P 1979. Revision of the Triatominae (Hemiptera, Reduviidae), and their significance as vector of Chaga's Disease. Bull Am Mus Nat Hist 163: 123-520.

Nei M 1973. Analysis of gene diversity in subdivided populations. Proc Natl Acad Sci USA 70: 3321-3323.

Nei M, Li WH 1979. Mathematical model for studying genetic variation in terms of restriction endonucleases. Proc Natl Acad Sci USA 76: 5269-5273.

Ramirez CJ, Jaramillo CA, del Pilar Delgado M, Pinto NA, Aguilera G, Guhl F 2005. Genetic structure of sylvatic, peridomestic and domestic populations of Triatoma dimidiata (Hemiptera: Reduviidae) from an endemic zone of Boyacá, Colombia. Acta Trop 93: 23-29.

Roderic DM 1996. TreeView: An application to display phylogenetic trees on personal computers. Computer Applications in the Biosciences 12: 357-358.

Rohlf FJ 1990. Rotational fit (Procrustes) methods. In FJ Rohlf, FL Bookstien (eds), Procceedings of the Michigan Morphometrics Workshop, The University of Michigan (Museum of Zoology), Ann Arbor, Michigan, Special Publication 2, p. 227-236. 
Rohlf FJ 2000. TPSREGR. Ver 1.26. Department of Ecology and Evolution, State University of New York, Stony Brook, NY. Website: http://life.bio.sunysb.edu/morph/.

Rohlf FJ 2003a. TPSDIG Ver 1.37. Department of Ecology and Evolution, State University of New York, Stony Brook, NY. Website: http://life.bio.sunysb.edu/morph/.

Rohlf FJ 2003b. TPSRELW Ver 1.31. Department of Ecology and Evolution, State University of New York, Stony Brook, NY. Website: http://life.bio.sunysb.edu/morph/.

Slatkin M, Barton NH 1989. A comparison of three indirect methods for estimating average levels of gene flow. Evolution 43: 1349-1368.

Sneath PH, Sokal RR 1973. Numerical Taxonomy, Freeman, San Francisco.
Welsh J, Pretzman C, Postic D, Saint Girons I, Baranton G, McClelland M 1992. Genomic fingerprinting by arbitrarily primed polymerase chain reaction resolves Borrelia burgdosferi into three distinct phylogenetic groups. Int $J$ Syst Bacteriol 42: 370-377.

Whitman D 2005. Insect Phenotypic Plasticity: Diversity of Responses Editors: T.N. Ananthakrishnan: Formerly, Director, Entomology Research Institute, Chennai, India ISBN 1-57808-322-2, p. 210.

Wright S 1931. Evolution in Mendelian populations. Genetics 16: 97-159.

Wright S 1978. Evolution and the Genetics of Populations, vol. 4, Variability within and among Natural Populations. University of Chicago Press, Chicago, IL. 